\title{
Magnetic properties of pulsed laser deposition-fabricated isotropic Pr-Fe-B thick-films magnets for magnetic micro-machines
}

\author{
M. Nakano, S. Oshima, ${ }^{\text {a) }}$ T. Yanai, and H. Fukunaga \\ Graduate School of Engineering, Nagasaki University, Nagasaki 852-8521, Japan
}

(Presented 7 November 2013; received 23 September 2013; accepted 26 November 2013; published online 4 March 2014)

\begin{abstract}
A preparation of Pr-Fe-B thick-film magnets by using a PLD (Pulsed Laser Deposition) method with the energy density at approximately $50 \mathrm{~mJ} / \mathrm{m}^{2}$ using the laser power of $2 \mathrm{~W}$ was effective to obtain the required magnetic properties for the application to a multi-polarly magnetized rotor. The isotropic films mainly consisted of $\mathrm{Pr}_{2} \mathrm{Fe}_{14} \mathrm{~B}$ magnetic phase whose saturation magnetization is approximately $1.56 \mathrm{~T}$, however the remanence $\left(\mathrm{B}_{\mathrm{r}}\right)$ showed higher than $0.9 \mathrm{~T}$. The obtained value of $\mathrm{B}_{\mathrm{r}}$ was considered to be attributed to a remanence enhancement due to the interaction of $\operatorname{Pr}_{2} \mathrm{Fe}_{14} \mathrm{~B}$ hard magnetic phases. Resultantly, the coercivity and $(B H)_{\max }$ of the samples exceeded $600 \mathrm{kA} / \mathrm{m}$ and $115 \mathrm{~kJ} / \mathrm{m}^{3}$, respectively, which were larger than that of previously reported PLD-fabricated isotropic rare-earth based thick-films. @ 2014 AIP Publishing LLC. [http://dx.doi.org/10.1063/1.4867130]
\end{abstract}

\section{INTRODUCTION}

In order to advance a microelectro-mechanical systems (MEMS), small rare-earth magnets have been prepared. ${ }^{1-3} \mathrm{~A}$ lot of researchers worked on pulsed laser deposition (PLD) rare-earth films such as Nd-Fe-B, Sm-Co, and Sm-Fe-N ones. ${ }^{4-10}$ Recently, we found that the fabrication of a multipolarly magnetized rotor using isotropic Nd-Fe-B thick-film magnets is effective to develop a miniaturized cylindrical motor. ${ }^{11}$ The required values of coercivity, remanence, and $(B H)_{\max }$ for the thick-films applied to the rotor are $0.9 \mathrm{~T}$, $400 \mathrm{kA} / \mathrm{m}$, and $90 \mathrm{~kJ} / \mathrm{m}^{3}$, respectively, and we demonstrated that isotropic Nd-Fe-B/ $\alpha-\mathrm{Fe}$ nano-composite thick-films had sufficient values of remanence and $(B H)_{\max }$ by using the PLD method with the laser energy density at $100 \mathrm{~mJ} / \mathrm{m}^{2}{ }^{12}$ Furthermore, the usage of a small spot size of a laser beam, which means that a laser beam was focused on the surface of a target according to the focus distance, in the experiment showed a grain refinement without the adoption of additives in the microstructure of PLD-fabricated thick films. On the other hand, the coercivity value of the nano-composite samples was less than $400 \mathrm{kA} / \mathrm{m}$, namely it was difficult to achieve the reproducibility of required coercivity value. It is generally known that the magnetic crystalline anisotropy constant of a $\operatorname{Pr}_{2} \mathrm{Fe}_{14} \mathrm{~B}$ phase $\left(\mathrm{K}_{\mathrm{u}}=6.8 \mathrm{MJ} / \mathrm{m}^{3}\right)$ is larger by approximately $2.3 \mathrm{MJ} / \mathrm{m}^{3}$ than that of a $\mathrm{Nd}_{2} \mathrm{Fe}_{14} \mathrm{~B}$ phase $\left(\mathrm{K}_{\mathrm{u}}=4.5 \mathrm{MJ} / \mathrm{m}^{3}\right) .{ }^{13}$

This contribution reports the ablation of $\mathrm{Pr}-\mathrm{Fe}-\mathrm{B}$ targets with various compositions by using the small spot size and the evaluation on the properties of the obtained samples. Resultantly, the laser energy density at approximately $50 \mathrm{~mJ} / \mathrm{mm}^{2}$ using the laser power of $2 \mathrm{~W}$ enabled us to obtain the required properties. It was also considered that the origin of superior magnetic properties is attributed to a remanence enhancement due to the magnetic interaction between $\mathrm{Pr}_{2} \mathrm{Fe}_{14} \mathrm{~B}$ grains.

\footnotetext{
${ }^{\text {a) }}$ Author to whom correspondence should be addressed. Electronic mail: 52113206@cc.nagasaki-u.ac.jp.
}

\section{EXPRIMENTAL PROCEDURE}

The Pr-Fe-B targets with various compositions were ablated by an Nd-YAG pulse laser (wave length $=355 \mathrm{~nm}$, frequency of the wave $=30 \mathrm{~Hz}$ ). Each film was deposited on a Ta substrate in the vacuum atmosphere of approximately $10^{-5} \mathrm{~Pa}$. The laser beam was focused on the surface of each rotating target, and the laser energy density varied by controlling the laser power range from 1 to $4 \mathrm{~W}$, which was measured with a power meter in front of the entrance lens of the chamber. A deposition rate higher than $10 \mu \mathrm{m} / \mathrm{h}$ could be obtained for a distance of $10 \mathrm{~mm}$ between a target and a substrate. All the as-deposited films thicker than $10 \mu \mathrm{m}$ were crystallized by a pulse annealing (PA) method in the vacuum atmosphere of $2-5 \times 10^{-5} \mathrm{~Pa}$. The pulse-annealing time was approximately $1.7 \mathrm{~s}$ with an infrared furnace at output power of $8 \mathrm{~kW}$, and then they were cooled down to room temperature. ${ }^{14}$

The magnetic properties of the samples were measured with a vibrating sample magnetometer (VSM) under the maximum applied magnetic field of $2.5 \mathrm{~T}$ after a magnetization with a pulsed magnetic field of $7 \mathrm{~T}$. All the films had isotropic magnetic properties, therefore in-plane ones were shown in the paper. The film thickness was measured with a micrometer, and the composition of each film was analyzed with an energy dispersive X-ray spectrometry (EDX). Furthermore, the crystalline structure of each film was observed by using a X-ray diffraction.

\section{RESULTS AND DISCUSSION}

\section{A. Magnetic properties and crystalline structure of $\mathrm{Pr}-\mathrm{Fe}-\mathrm{B} / \alpha-\mathrm{Fe}$ together with $\mathrm{Nd}-\mathrm{Fe}-\mathrm{B} / \alpha-\mathrm{Fe}$ nano-composite thick-film magnets prepared by using the laser power of $4 \mathrm{~W}$}

Figure 1 shows the values of remanence and coercivity of $\mathrm{Pr}-\mathrm{Fe}-\mathrm{B} / \alpha-\mathrm{Fe}$ together with $\mathrm{Nd}-\mathrm{Fe}-\mathrm{B} / \alpha-\mathrm{Fe}$ thick-film magnets prepared by using the laser energy density at approximately $100 \mathrm{~mJ} / \mathrm{mm}^{2}$ using the laser power of $4 \mathrm{~W}$. Each target composition was $\operatorname{Pr}_{2.4} \mathrm{Fe}_{14} \mathrm{~B}$ and $\mathrm{Nd}_{2.4} \mathrm{Fe}_{14} \mathrm{~B}$, respectively, and the 


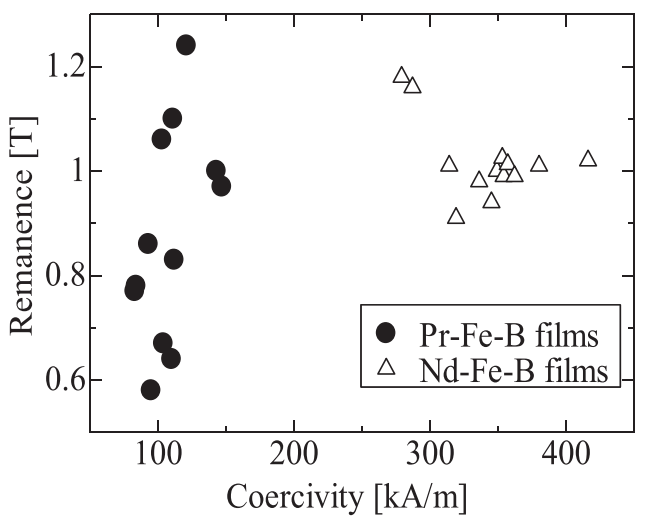

FIG. 1. Remanence and coercivity values of $\mathrm{Pr}-\mathrm{Fe}-\mathrm{B} / \alpha-\mathrm{Fe}$ and Nd-Fe-B/ $\alpha$-Fe nano-composite thick-films prepared by using the laser energy density at approximately $100 \mathrm{~mJ} / \mathrm{m}^{2}$ using the laser power of $4 \mathrm{~W}$. Each target composition was $\operatorname{Pr}_{2.4} \mathrm{Fe}_{14} \mathrm{~B}$ and $\mathrm{Nd}_{2.4} \mathrm{Fe}_{14} \mathrm{~B}$, respectively, and the magnetic properties of post-annealed films were indicated. The same deposition and post-annealing processes were carried out in all the samples.

magnetic properties of post-annealed films were indicated. The conditions of deposition and post-annealing processes were same in the both samples, and the results of Nd-Fe-B films shown in the figure have already been reported in Ref. 12. In addition, the rare-earth ( $\mathrm{Pr}$ or $\mathrm{Nd}$ ) composition range from 9 to 11 at. \% was almost the same in the both of nano-composite films, however, the magnetic properties were much different. Although the values of coercivity and remanence were higher than $300 \mathrm{kA} / \mathrm{m}$ and $0.9 \mathrm{~T}$ in the $\mathrm{Nd}-\mathrm{Fe}-\mathrm{B} / \alpha-\mathrm{Fe}$ thick-film magnets, the coercivity and remanence values of $\mathrm{Pr}-\mathrm{Fe}-\mathrm{B} / \alpha$-Fe films were lower and more fluctuating, respectively. In order to investigate the different properties for the both films, the observation of crystalline structure together with the measurement on $\mathrm{M}-\mathrm{H}$ loops of the as-deposited films were carried out. As previously reported in Ref. 12, an $\alpha$-Fe crystalline phase was mainly observed in an as-deposited $\mathrm{Nd}-\mathrm{Fe}-\mathrm{B} / \alpha-\mathrm{Fe}$ film. On the other hand, an as-deposited $\mathrm{Pr}-\mathrm{Fe}-\mathrm{B} / \alpha-\mathrm{Fe}$ film had the diffraction peaks of a $\operatorname{Pr}_{2} \mathrm{Fe}_{14} \mathrm{~B}$ crystalline phase together with an $\alpha$-Fe phase. In addition, the M-H loop of as-deposited Pr-Fe- $\mathrm{B} / \alpha-\mathrm{Fe}$ film widened compared with that of $\mathrm{Nd}-\mathrm{Fe}-\mathrm{B} / \alpha-\mathrm{Fe}$ one. It is generally known that the amorphous structure of the hard magnetic phase before an annealing process is indispensable to achieve good magnetic properties in nano-composite magnets. ${ }^{15}$ It, therefore, was considered that we had difficulty in obtaining large coercivity values of $\mathrm{Pr}-\mathrm{Fe}-\mathrm{B} / \alpha-\mathrm{Fe}$ films as shown in Fig. 1. Furthermore, the substrate temperatures of the both films during the deposition with the laser power of $4 \mathrm{~W}$ were confirmed to be approximately $673 \mathrm{~K}$ which suggests the requirement of reduction in the substrate temperature to suppress the crystallization of $\mathrm{Pr}_{2} \mathrm{Fe}_{14} \mathrm{~B}$ phase.

\section{B. Magnetic properties of thick-film magnets prepared by ablating a Pr-Fe-B target with a small spot size of a laser beam under the laser power range between 1 and $3 \mathrm{~W}$}

We have already reported that the rise of substrate temperature is attributed to the heat radiation from a target during the fabrication of Fe-Pt films by using the PLD, ${ }^{16}$

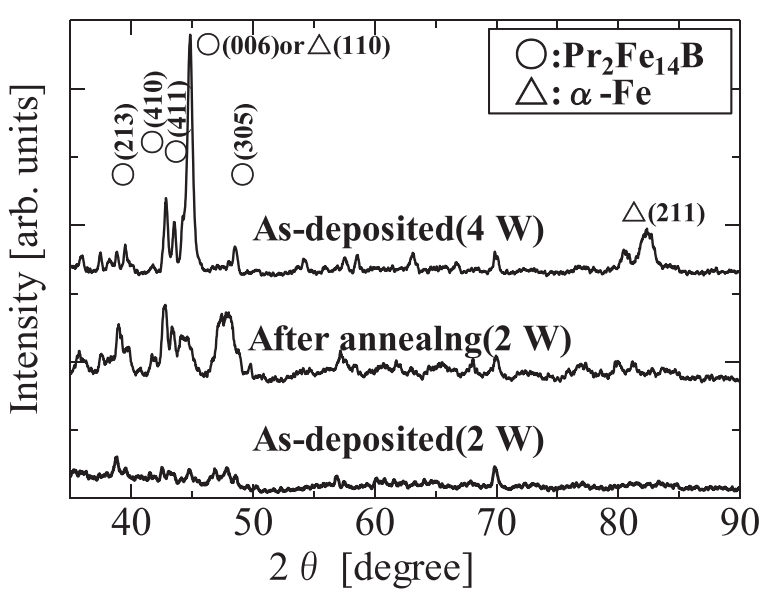

FIG. 2. X-ray diffraction patterns of as-deposited and annealed Pr-Fe-B films prepared by using a $\operatorname{Pr}_{2.4} \mathrm{Fe}_{14} \mathrm{~B}$ target together with the laser power of $2 \mathrm{~W}$. XRD pattern of an as-deposited film prepared at $4 \mathrm{~W}$ was also shown.

therefore the reduction in the laser power from 3 to $1 \mathrm{~W}$ was carried out in order to suppress the crystallization of $\mathrm{Pr}_{2} \mathrm{Fe}_{14} \mathrm{~B}$ phase. Resultantly, it was clarified that the use of $2 \mathrm{~W}$ (Laser energy density: Higher than $50 \mathrm{~mJ} / \mathrm{mm}^{2}$ ) is an optimum condition to prepare a thick film with good magnetic properties under the high deposition rate. Namely, in the case of $3 \mathrm{~W}$, the magnetic properties did not change compared with those of films prepared at $4 \mathrm{~W}$, and we had difficulty in obtaining relatively high deposition rate larger than $10 \mu \mathrm{m} / \mathrm{h}$ at the power of $1 \mathrm{~W}$.

Figure 2 shows the X-ray diffraction patterns of asdeposited and annealed Pr-Fe-B films prepared by using a $\operatorname{Pr}_{2.4} \mathrm{Fe}_{14} \mathrm{~B}$ target together with the laser power of $2 \mathrm{~W}$. Here, an XRD pattern of an as-deposited film prepared at $4 \mathrm{~W}$ was also shown in the figure. The film compositions for the $2 \mathrm{~W}$ case were almost the same as the stoichiometric one. The diffraction peaks corresponding to $\mathrm{Pr}_{2} \mathrm{Fe}_{14} \mathrm{~B}$ phases in the samples prepared at $2 \mathrm{~W}$ were not strong compared with those for the $4 \mathrm{~W}$ case. Furthermore, the average grain size of $\mathrm{Pr}_{2} \mathrm{Fe}_{14} \mathrm{~B}$ phase was approximately $18 \mathrm{~nm}$ according to the estimation of Scherrer's equation. ${ }^{17}$ The magnetic properties of the annealed films were shown in Fig. 3. Although the

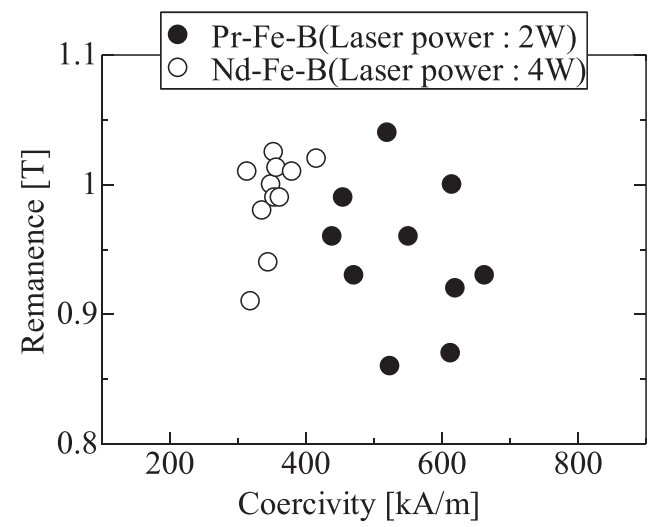

FIG. 3. Coercivity and remanence values of annealed Pr-Fe-B and Nd-Fe-B/ $\alpha$-Fe thick-films. The Pr-Fe-B films were prepared by using the laser energy density at approximately $50 \mathrm{~mJ} / \mathrm{m}^{2}$ using the laser power of $2 \mathrm{~W}$. The plots of $\mathrm{Nd}-\mathrm{Fe}-\mathrm{B}$ ones were also shown in Fig. 1. The remanence values of Pr-Fe-B thick-films fluctuated between 0.85 and $1.05 \mathrm{~T}$, however the values of coercivity were higher compared with those of $\mathrm{Nd}-\mathrm{Fe}-\mathrm{B} / \alpha-\mathrm{Fe}$ thick-films. 


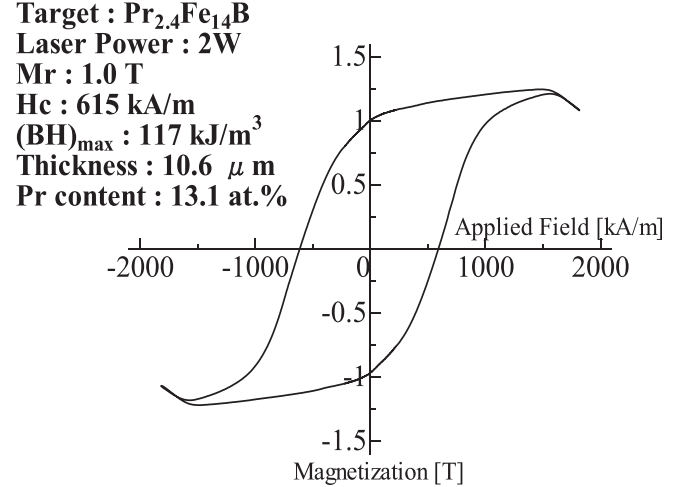

FIG. 4. In-plane M-H loop of an annealed Pr-Fe-B film which had the largest $(B H)_{\max }$ value in the experiment. The film was prepared by using the laser energy density at approximately $50 \mathrm{~mJ} / \mathrm{mm}^{2}$ using the laser power of $2 \mathrm{~W}$. $\left(\mathrm{Pr}_{2.4} \mathrm{Fe}_{14} \mathrm{~B}\right.$ target).

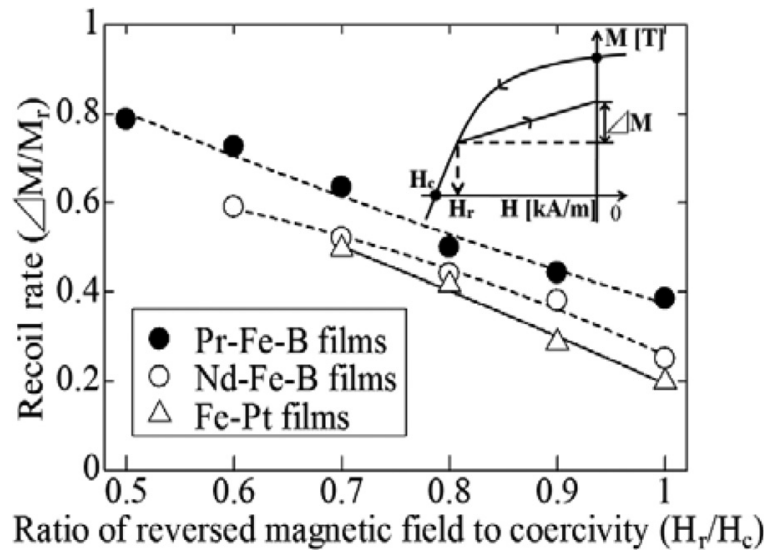

FIG. 5. Recoil rates of Pr-Fe-B, Nd-Fe-B/ $\alpha-\mathrm{Fe}$ nano-composite, and Fe-Pt thick-films prepared by using the PLD method. As shown in the inset figure, the horizontal and vertical axes showed a ratio of reversed magnetic field to coercivity and a recoil rate, respectively.

values of remanence fluctuated from 0.85 to $1.05 \mathrm{~T}$, almost all the coercivity values of the thick-films exceeded $400 \mathrm{kA} / \mathrm{m}$. We also confirmed $(B H)_{\max }$ values became higher than $90 \mathrm{~kJ} / \mathrm{m}^{3}$. Figure 4 shows a M-H loop of a sample which had the largest $(B H)_{\max }$ through the experiments. In order to evaluate the exchange interaction, a recoil rate of the above-mentioned Pr-Fe-B thick-film magnet was measured. Here, the rates of previously reported PLD-fabricated $\mathrm{Nd}-\mathrm{Fe}-\mathrm{B} / \alpha-\mathrm{Fe}^{12}$ and $\mathrm{Fe}-\mathrm{Pt}$ films ${ }^{16}$ were also plotted in Fig. 5. It was found that the recoil behavior of the Pr-Fe-B thick film is superior to those of other PLD-made films together with that of a nano-composite bulk magnet with $\mathrm{Nd}_{2} \mathrm{Fe}_{14} \mathrm{~B}$ and $\alpha$-Fe phases. ${ }^{15}$

From the above results, it is considered that the grain refinement of approximately $20 \mathrm{~nm}$ together with the good recoil rate in a Pr-Fe-B film with similar stoichiometric composition enables us to obtain the exchange interaction between the hard magnetic phase of $\operatorname{Pr}_{2} \mathrm{Fe}_{14} \mathrm{~B}$. Resultantly, we succeeded in achieving the large coercivity and the high $(B H)_{\max }$ value.

\section{CONCLUSION}

Use of a Pr-Fe-B target together with an optimum laser condition enabled us to obtain isotropic thick-film magnets with superior magnetic properties compared with those of previously reported rare-earth based thick-films by using the PLD method with the deposition rate higher than $10 \mu \mathrm{m} / \mathrm{h}$. In particular, the reduction in the laser power from 4 to $2 \mathrm{~W}$ leaded to suppress the heating of a substrate temperature and to obtain amorphous structure of an as-deposited Pr-Fe-B film. Resultantly, the coercivity and $(B H)_{\max }$ of the samples exceeded $600 \mathrm{kA} / \mathrm{m}$ and $115 \mathrm{~kJ} / \mathrm{m}^{3}$, respectively, after a post-annealing. The origin of the good properties of a post-annealed film is considered to be attributed to the exchange interaction between $\operatorname{Pr}_{2} \mathrm{Fe}_{14} \mathrm{~B}$ hard grains.

${ }^{1} \mathrm{O}$. Cugat, in Proceeding of the 16th International Workshop on Rare Earth Magnets and Their Applications (Ronton Press, 2002), p. 478.

${ }^{2}$ P. McGuiness, D. Jezersek, S. Kobe, B. Markoh, S. Spaic, and B. Saje, J. Magn. Magn. Mater. 305, 177 (2006).

${ }^{3}$ A. Walther, C. Marcoux, B. Desloges, R. Grechishkin, D. Givord, and N. M. Dempsey, J. Magn. Magn. Mater. 321, 590 (2009).

${ }^{4}$ A. J. M. Geurtsen, J. C. S. Kools, L. de Wit, and J. C. Lodder, Appl. Surf. Sci. 96-98, 887 (1996).

${ }^{5}$ F. J. Cadieu, R. Rani, X. R. Qian, and L. Chen, J. Appl. Phys. 83, 6247 (1998).

${ }^{6}$ S. Y. Xu, X. J. Huang, C. K. Ong, S. L. Lim, Y. L. Chang, Z. Yang, Z. W. Li, and H. B. Nie, J. Magn. Magn. Mater. 222, 182 (2000).

${ }^{7}$ J. M. Song, H. Sadakata, M. Nakano, Y. Kanai, H. Fukunaga, and J. G. Koh, IEEE Trans. Magn. 35, 3052 (1999).

${ }^{8}$ U. Hannemanm, S. Fahler, V. Neu, B. Holzapfel, and L. Schultz, IEEE Trans. Magn. 38, 2805 (2002).

${ }^{9}$ S. Fahler, V. Neu, M. Weisheit, U. Hannemann, S. Leinert, A. Singh, A. Kwon, S. Melcher, B. Holzapfel, and L. Schultz, in Proceedings of 18th International Workshop on Rare Earth Permanent Magnets and Their Applications (2004), p. 566.

${ }^{10}$ V. Neu, S. Sawatzki, M. Kopte, C. Mickel, and L. Schultz, IEEE Trans. Magn. 48, 3599 (2012).

${ }^{11}$ F. Yamashita, S. Nishimura, O. Kobayashi, M. Itoh, M. Nakano, H. Fukunaga, and K. Ishiyama, J. Appl. Phys. 109, 07A712 (2011).

${ }^{12}$ M. Nakano, K. Motomura, T. Yanai, and H. Fukunaga, Dig. ISAMMA 2013 2014, TB-01.

${ }^{13}$ K. H. J. Buschow, in Ferromagnetic Materials (North-Holland Publishing, 1988), Vol. 4.

${ }^{14}$ H. Fukunaga, K. Tokunaga, and J. M. Song, IEEE Trans. Magn. 38, 2970 (2002).

${ }^{15}$ C. L. Harland, L. H. Lewis, Z. Chen, and B. M. Ma, J. Magn. Magn. Mater. 271, 53 (2004).

${ }^{16}$ M. Nakano, W. Oniki, T. Yanai, and H. Fukunaga, J. Appl. Phys. 109, 07A723 (2011).

${ }^{17}$ B. D. Cullity, Element of X-ray Diffraction (Addison-Wesley, Reading, MA, 1962). 